\title{
FINGI(DORES) DE SI MESMOS: DORES FINGIDAS E REAIS NA ORATÓRIA ROMANA
}

\author{
Paulo Sérgio de Vasconcellos` \\ Universidade Estadual de Campinas
}

\begin{abstract}
This paper focuses on the conceptions of ethos and pathos in Roman rhetoric in order to investigate how far were ancient Romans from our notion of poetical persona. Its title dialogues with the poem "Autopsicografia" by Fernando Pessoa, whose "feigned pain" has a correlate in Ciceronian fictus dolor. This preliminary consideration is part of our broader investigation on the reception of subjective poetry in ancient Rome, and more widely in classical studies.
\end{abstract}

KEYWORDS: Roman rhetoric; ethos; pathos.

ossa pesquisa sobre o biografismo e a recepção da poesia amorosa romana na Antiguidade e nos estudos clássicos ${ }^{1}$ tem-nos levado a reler os tratados de retórica antiga em busca de considerações teóricas que possam nos mostrar quão perto ou quão distantes estiveram os antigos romanos das nossas noções de "eu-poético" ou "persona poética", uma instância discursiva a distinguir-se do autor empírico ou, pelo menos, a problematizar-se, dada a complexidade da questão. Por mais que os modos de recepção sejam variáveis sincrônica e diacronicamente e não se possa ter a pretensão de controlá-los, parece consensual hoje que o biografismo ingênuo de certas leituras do passado, ainda que resista entre o público leigo de poesia, está desprestigiado na academia, a "comunidade interpretativa"

^ odoricano@ig.com.br

${ }^{1}$ Projeto que contou, recentemente, com apoio da FAPESP (processo 2013/ 15811-4). 
a que os latinistas pertencem. Chamamos de biografismo a tendência a interpretar dados de uma obra literária como expressão do autor empírico, sobretudo quando se trata de poesia em primeira pessoa; nessa abordagem, vicissitudes narradas na poesia são interpretadas como relato biográfico; sentimentos expressos são a expressão subjetiva do autor empírico; o nome próprio do autor (Catulo, Propércio...) é tratado como o nome de uma certidão de batismo moderna, sem que se levem em conta elementos como as convenções genéricas das obras, a ficcionalidade da expressão poética e o desconhecimento do contexto preciso da recepção das obras. Não se trata, porém, de cair no outro extremo da desconsideração pura e simples da categoria do autor, como no intertextualist fundamentalism de que fala Hinds (1998, p. 48), mas de pôr em discussão os modos mesmos de representação da subjetividade no discurso poético.

Em nossa incursão pela retórica romana, chama-nos a atenção o que Cícero e Quintiliano dizem sobre ethos e pathos e as associações possíveis com nossas distinções entre autor empírico ou autor de carne e osso e "eu-poético"; e é a esse ponto que dedicaremos nossas considerações. Em síntese, o que vemos em certas passagens dos tratados de retórica romanos é que se chega próximo de uma distinção entre a persona do locutor e o autor histórico do discurso, mas essa distinção nunca é claramente feita e, muito menos, aplicada ao caso da poesia em primeira pessoa.

No Orator, Cícero afirma que, ao não se levar em conta o decorum, ${ }^{2}$ erra-se muito "nos poemas e no discurso oratório" (et in poematis et in oratione peccatur). ${ }^{3}$ Ora, mencionando os fatores a levar em consideração para a busca do que seria decoroso quanto às ideias e palavras (non in sententiis solum sed etiam in uerbis), ${ }^{4}$ Cícero se refere à necessidade de ajustar o discurso às personae dos que discursam e dos que ouvem (et in personis et eorum qui dicunt et eorum qui audiunt). ${ }^{5}$ Há quem erre no tratamento de sua persona, da dos juízes ou até mesmo dos adversários (at persona alii peccant aut sua aut iudicum aut etiam aduersariorum) não apenas quanto ao conteúdo do que se diz, mas quanto à expressão verbal (nec re solum, sed saepe uerbo). ${ }^{6}$ Portanto, o emissor

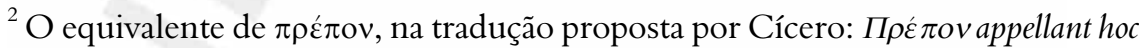
Graeci, nos dicamus sane decorum (XXI, 70).

${ }^{3} \mathrm{XXI}, 70$.

${ }^{4} \mathrm{XXI}, 71$.

${ }^{5}$ XXI, 71. Em Orator, 35, 125, Cícero preceitua que o orador deve ter a sabedoria de adaptar o discurso às circunstâncias e às pessoas [Vt si temporum personarumque moderator].

${ }^{6} \mathrm{XXI}, 72$.
} 
(qui dicunt) constrói, no discurso, uma imagem de si mesmo, reveste-se de uma "máscara", adequada às circunstâncias da enunciação; só assim se entende como alguém possa errar no tratamento de sua própria persona por não ter sabido adaptar res, uerba, actio às circunstâncias particulares que devem moldar o discurso.

A possibilidade de um erro no tratamento da própria persona revela que tudo, na prática oratória, é planejado detalhadamente, inclusive a impressão que se deseja transmitir de si mesmo; um discurso deixaria transparecer não a personalidade do autor empírico, mas uma "persona" meticulosamente preparada e ensaiada. Mas e o poeta, que, no uso do decoro, fora comparado ao orador? Ele não construiria para si mesmo uma certa persona? Todavia, quando Cícero retorna aos poetas, o que está em jogo é apenas a adequação do discurso a determinada personagem. ${ }^{7}$ Assim, o poeta erra ao atribuir um discurso probo a um homem ímprobo ou um estulto a um homem sábio (qui peccat etiam, cum probam orationem affingit improbo stultoue sapientis).

No De oratore, afirma-se que o poeta tem um campo de atuação muito próximo daquele do orador: est enim finitimus oratori poeta (I, 70); ${ }^{9}$ quibus est proxima cognatio cum oratoribus (III, 27). ${ }^{10}$ Entretanto, ao precisar as semelhanças entre os dois (I, 70), menciona-se apenas o trato com os uerba:

\footnotetext{
${ }^{7}$ Também no De officiis I, 97-98; em Horácio, na Arte Poética, v. 119-127, preceituase que os personagens da tradição mítica devem ser retratados de acordo com o decoro, isto é, com as características que tradicionalmente se atribuem a eles (Aquiles será impiger, iracundus, inexorabilis, acer, etc.); se se inventa um personagem novo, deve-se cuidar de que tenha coerência do princípio ao fim.

${ }^{8}$ XXII, 74 .

9 "Um pouco mais restrito quanto ao ritmo, mais livre, porém, na licença verbal, aliado e quase seu par nas muitas espécies de adorno" [Numeris astrictior paulo, uerborum autem licentia liberior, multis uero ornandi generibus socius ac paene par].

${ }^{10}$ A questão deveria ser posta com frequência, a se julgar por esta passagem do Orator, 66: "Pois até mesmo os poetas levantaram a questão sobre o que é que os distinguiria dos oradores: parecia-lhe, antes, que, sobretudo, pelo ritmo e pelo verso, mas agora, entre os oradores, o próprio ritmo se difundiu" [Nam etiam poetae quaestionem attulerunt quid nam esset illud, quo ipsi differrent ab oratoribus: numero maxime uidebantur antea et uersu, nunc apud oratores iam ipse numerus increbruit.]. Se, primeiramente, achava-se que a distinção se encontrava apenas no ritmo regular da poesia (ou pela liberdade maior dos poetas no uso das figuras: De oratore III, 153; Quintiliano VIII, 6, 19), justifica-se plenamente estudar a teoria da antiga retórica para especular, a partir de suas considerações sobre o discurso do orador, o que poderiam ser concepções antigas sobre o discurso poético.
} 
o poeta está um pouco mais preso ao ritmo (numeris ascritior paulo), tem uma licença maior com as palavras (uerborum autem licentia liberior), embora seja quase par do orador no uso do ornato (multis uero ornandi generibus socius ac paene par). ${ }^{11}$ Em nenhum momento, a semelhança entre poeta $\mathrm{e}$ orador advém da assunção de uma persona elaborada discursivamente para a produção de certos efeitos sobre os receptores.

A construção do ethos no discurso, adequado a certa persona, não traria como corolário a ideia de que, na poesia, o ethos construído não seria necessariamente enraizado na biografia do emissor? Lembremos que Aristóteles apresenta o ethos como $\pi$ ío $\tau \imath \varsigma$, um dos três meios de persuasão, ${ }^{12}$

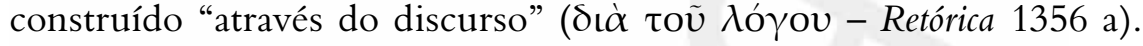
Obtém-se persuasão pelo ethos quando o discurso torna o orador digno

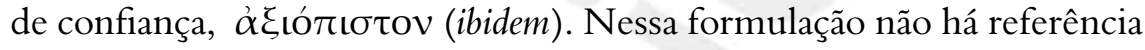
a um ethos construído precedentemente ao discurso (que poderia ter sido mencionado entre as provas não "técnicas"): em suma, a credibilidade parece se construir como um efeito do discurso, independentemente do ethos prévio, da estima de que goza socialmente o orador. ${ }^{13}$

Em Cícero, ao contrário do que ocorre em Aristóteles, ${ }^{14}$ há, de forma

\footnotetext{
${ }^{11}$ Sobre a diferença entre o discurso do orador e do poeta, Cícero se detém no Orator, 66-8.

${ }^{12}$ Sobre a noção de pístis, cf. Wisse, 1989, p. 14 et seq. Os "meios de persuasão"

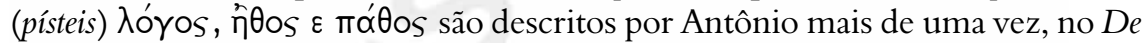
oratore (por exemplo, em II, 115), sem que se citem os nomes gregos empregados por Aristóteles. Teria Cícero lido a Retórica? Segundo Wisse, é provável, embora não se possa comprová-lo (cf. Wisse, in May, 2002, p. 385).

${ }^{13}$ Cf. Montefusco, 1992, p. 246: "Aristóteles nos diz muito claramente que o ethos do falante consiste em parecer crível por efeito do discurso, e não de uma ideia preconcebida de seu caráter" [Aristotele ci dice molto chiaramente chel'ethos del parlante consiste nell'apparire credibile per l'effetto del suo discorso, e non di un'idea preconcetta sul

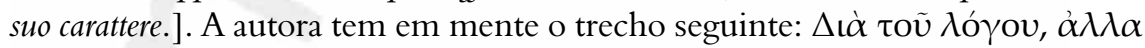

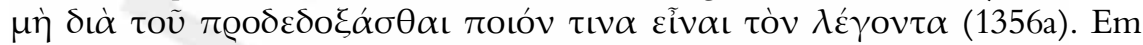
Aristóteles a ênfase é no caráter técnico da criação do ethos no discurso, não na utilização de um ethos preexistente, que, de fato, não seria um meio de persuasão "técnico". Cf. Uelding, op. cit., p. 1520: "Para Aristóteles, entretanto, a reputação que, antes de seu discurso, tem o orador não desempenha nenhum papel no meio ético de persuasão" [Für Aristoteles spielt aber der Ruf, den ein Redner vor seinem Vortrag hat, beim ethischen Überzeugungs mittel keine Rolle.].

${ }^{14}$ Cf. Guérin, op. cit., p. 9: "Aristóteles concebia, assim, um primeiro $๊$ †os, que se pode qualificar de referencial, reunindo as coordenadas reais do orador: idade, sexo, etnia, contexto político. Mas ele acrescia um segundo tipo de ñ̂̆os, correspondente
} 
clara, previamente ao discurso, um ethos do orador que tem seu peso, sua autoridade e, portanto, papel importante na persuasão. ${ }^{15}$ Todavia, no mesmo Cícero também encontramos, segundo nos parece, na tradição aristotélica, um ethos formal, "técnico", sem referência a mores prévios, construído no discurso, ${ }^{16}$ incluindo-se aqui a actio.

No De oratore, II, 182, ${ }^{17}$ tratando da eficácia oratória de um ethos que conquista a benevolência para o orador e seu cliente, Antônio diz:

à elaboração discursiva da imagem do orador e destinado a estabelecer sua credibilidade" [Aristote concevait ainsi un premier j̃̈los, que l'on peut qualifier de réferentiel, regroupant les coordonnées réelles de l'orateur: age, sexe, ethnie, environnement politique. Mais il y ajoutait un second type d' j̄ंos, correspondant à l'élaboration discursive de l'image de l'orateur et venant asseoir sa crédibilité.]. $\mathrm{Na}$ Retórica, porém, interessa, como prova "técnica", o ethos que é produto do discurso [cf. Wisse, 1989, p. 3536). A retórica ciceroniana desloca o interesse para o ethos prévio ao discurso, sem descurar do outro tipo. Cf., por exemplo, May, 1988, p. 9: “A concepção aristotélica de um ethos retratado somente através do discurso não era, para o orador romano, nem aceitável nem adequada" [Aristotle's conception of an ethos portrayed only through the medium of a speech was, for the Roman orator, neither acceptable nor adequate.].

${ }^{15}$ Cf. Montefusco, op. cit., p. 253: "O ethos ciceroniano, porém, se funda, sobretudo, numa moralidade que é resultado de um comportamento passado, que predispõe benevolamente o ouvinte" [L'ethos ciceroniano si basa invece per lo più su una moralità che è risultato di un comportamento passato, che predispone benevolmente l'ascoltatore.]. Wisse (2002, p. 386, nota 15) observa que em Aristóteles e em Cícero, no tratamento do ethos, está em questão a oratória judiciária ["Note-se que ethos em nenhum dos dois autores inclui personagens diversos dos efetivos participantes em um julgamento - juristas e clientes" (Note that ethos in neither author includes characters other than the direct participants in a trial - pleaders and clientes).]. Sobre as semelhanças e diferenças entre a concepção de ethos ciceroniana e a de Isócrates, cf. Scatolin, op. cit., 118-120.

${ }^{16}$ Cf. Scatolin, 2009, p. 256. É preciso ressaltar, porém, que Cícero não emprega a palavra grega, hoje tão comum nos estudos do discurso; o termo empregado é mores, que tem ressonâncias difíceis de verter com um só termo numa língua moderna. Cf., porém, Guérin, op. cit., p. 13: "Ao contrário da abordagem aristotélica, esses sinais éticos serão sistematicamente apresentados por Cícero como verdadeiros: em nenhum lugar se sugerirá a possibilidade de uma construção da persona que esteja separada das qualidades reais do orador" [À l'inverse de l'approche aristotélicienne, ces signes éthiques seront systématiquement presentes comme véraces par Cicéron: nulle part ne sera suggérée la possibilité d'une construction de la "persona" qui soit détachée des qualités réelles de l'orateur.].

${ }^{17}$ Texto da série Les Belles Lettres: Cicéron, 1966. 
Valet igitur multum ad uincendum probari mores et instituta et facta et uitam et eorum, qui agent causas, et eorum pro quibus, et item improbari aduersariorum, animosque eorum, apud quos agetur, conciliari quam maxume ad beneuolentiam quom erga oratorem tum erga illum, pro quo dicet orator. Conciliantur autem animi dignitate hominis, rebus gestis, existumatione uitae; quae facilius ornari possunt, si modo sunt, quam fingi, si nulla sunt.

Tem grande importância, pois, para a vitória, retratar como probos (probari) ${ }^{18}$ os costumes (mores), os princípios, os feitos e a vida tanto daqueles que defenderão a causa como daqueles que serão dela beneficiários e, do mesmo modo, retratar como ímprobos (improbari) os dos adversários, e conquistar o mais possível a benevolência junto àqueles diante dos quais a causa será defendida, tanto para com o orador quanto para com aquele em defesa do qual o orador discursará. Ora, conquistam-se os ânimos por meio da dignidade da pessoa, suas realizações, a estima pela vida, coisas que se pode mais facilmente embelezar, se existem, do que inventar, se não existem.

Na passagem acima, embora a ênfase inicial seja num ethos preexistente de alguém que conquistará a benevolência do público por qualidades socialmente estimadas, na sequência admite-se a possibilidade de se representar (fingi) no discurso algo que não existe. O orador deverá construir um ethos positivo para si e seus clientes, ${ }^{19}$ colocando em evidência valores como a dignitas, os feitos, a reputação de que se goza (dignitate hominis, rebus gestis, existimationem uitae), tarefa mais difícil se essas qualidades não existem. Se não se diz claramente que o orador vai fingir para si qualidades que não possui, aventa-se a possibilidade de que isso ocorra: vai-se "inventar" um ethos para o réu que se defende; quanto a seu próprio ethos, deve ter as características que Antônio menciona; ora, se o orador

${ }^{18} \mathrm{O}$ verbo, na ativa, pode ter o significado que o $O L D$ apresenta no item 6 e que nos parece em causa aqui: "fazer com que seja visto favoravelmente, conseguir aprovação para" [to cause to be favourably regarded, win approval for]. Sobre a ambiguidade de probare, "to approve of" e "to win approval for", cf. Leeman et alii, 1989, p. 136.

${ }^{19} \mathrm{Na}$ tradição romana, é preciso construir um ethos não apenas para o orador (e um negativo para a parte contrária), mas para o cliente (commendationem habet nostram aut eorum quos defendimus, II, 114). Como se sabe, na Grécia era o próprio réu que se defendia (por vezes decorando um discurso preparado por outro); assim, Aristóteles jamais menciona o ethos do cliente (cf. Wisse, 1989, p. 32). Em Roma, a figura do advogado, que discursa em defesa de outros, obriga à criação de um ethos adequado para o próprio advogado e para seu cliente. 
carece de uma delas... a conclusão que se pode extrair é que ele deverá, também, "fingi-la", inventá-la. ${ }^{20}$ Notemos, por fim, que a generalidade do que diz Antônio leva os tradutores a opções muito diversas: Antônio está falando em "fingir" um ethos para o cliente ou para o orador? Para nós, tendo em vista o contexto e a imprecisão da expressão, compreenderemos que a prescrição se aplica a ambos. ${ }^{21}$ Note-se que na sequência, Antônio explicitará qualidades desejadas no orador e especifica que se trata, agora, exclusivamente do orador (sed haec adiuuant in oratore...). Compare-se uma tradução italiana (que aplica a ideia somente ao cliente) e uma francesa (que parece restringir-se mais especificamente ao orador):

Ci si accattivano gli animi parlando dell'onoratezza del cliente, delle sue imprese, della sua buona reputazione: qualità che è più facile ornare se solo esistono, piuttosto che inventare se non esistono. ${ }^{22}$

Or ce qui nous concilie la bienveillance, c'est la dignité de notre caractère, ce sont nos actions louables, la considération qu'inspire notre vie: toutes choses qu'il est plus facile d'embellir que de feindre quand elles n'existent pas. D'autres qualités ajoutent chez l'orateur à l'effet produit... ${ }^{23}$

Antônio, no mesmo De oratore (II, 182), ao tratar dos afetos que o orador deve "mover", menciona as características de caráter a transmitir no discurso sem mencionar a necessidade de se possuir, de fato, certas qualidades:

${ }^{20}$ Cf. Wisse, 1989, p. 234-235: "O mesmo, pois, vale para a oração subordinada quasi... si nulla sunt, na qual Antônio destaca que as qualificações necessárias podem estar faltando - no 'patronus' ou no 'cliens'" [The same, then, goes for the subclause "quasi... si nulla sunt", in which Antonius points out that the necessary qualifications may be lacking - in the "patronus" or in the "cliens".]. Para uma análise detalhada de toda a passagem 182-184, de interpretação controversa, cf. Leeman et alii, 1989, p. 127128; os autores também julgam que o passo em questão se refere ao advogado e ao cliente: "Mas o ethos em si se refere, como se evidencia no genérico 'hominis', ao patronus e ao cliens" [Aber das Ethos selbst bezieht sich, wie sich aus dem allgemeinem hominis ergibit, auf patronus und cliens. - p. 127].

${ }^{21}$ Como compreende, por exemplo, o tradutor da série Loeb: "Ora, conquistamse os sentimentos através do mérito de um homem" [Now feelings are won over by a man's merit...] (Cicero, 1967, p. 327).

${ }^{22}$ Tradução de Mario Martina, apud Cicerone, op. cit., p. 427.

${ }^{23}$ Tradução de Courbaud na série Les Belles Lettres já citada, p. 79. 
Facilitatis, liberalitatis, mansuetudinis, pietatis, grati animi, non appetentis non auidi signa proferre perutile est...

É muito útil emitir sinais ${ }^{24}$ de afabilidade, liberalidade, mansidão, piedade, gratidão, de alguém que não ambiciona, não é cobiçoso.

O orador deve parecer tal qual deseja parecer: Si uero ad sequetur, ut talis uideatur qualem se videri uelit (II, 176).

Tem admirável eficácia exibir os mores adequados. Ressalta-se, no De oratore, a importância de que os réus, englobando-se aqui todos aqueles cujo interesse é implicado na discussão, sejam retratados (exprimere) da forma mais positiva. ${ }^{25}$ Por outro lado, "tão grande é o efeito de uma espécie de sensibilidade e um certo modo de dizer que o discurso como que molda uma imagem (effingat) dos mores do orador". ${ }^{26}$ Claramente, não se trata do caráter real, preexistente ao discurso, mas de um ethos construído pelo discurso. ${ }^{27}$ Note-se que tanto exprimere quanto effingere são verbos das artes plásticas: ${ }^{28}$ o orador modela um ethos para si, assim como para o réu que ele defende e para o adversário.

${ }^{24}$ Cf. os signa doloristui (II, 190) que o orador deve exibir, nas palavras, pensamentos, voz, semblante e pranto, para suscitar a misericórdia do juiz.

25 "Ora, chamo réus não apenas os que são acusados, mas todos aqueles sobre cujo caso se discute, pois assim se dizia antigamente. Portanto, descrever seus costumes, no discurso, como justos, íntegros, escrupulosos, cautos, sofredores de injustiças tem uma espécie de eficácia admirável" [II, 183-184. Reos autem appello non eos modo qui arguuntur, sed omnis quorum de re disceptatur; sic enim olim loquebantur. Horum igitur exprimere mores oratione iustos, integros, religiosos, timidos, perferentis iniuriarum mirum quiddam ualet.].

${ }^{26}$ Tantum autem efficitur sensu quodam ac ratione dicendi, ut quasi mores oratoris effingat oratio (II, 184).

${ }^{27}$ Cf. Leeman et alii, op. cit., p. 140: "Não se trata do caráter real, mas do Ethos (quasi)" [Es handelt sich nicht um den wirklichen Charakter, sondern um das Ethos (quasi)]. O discurso do orador deve parecer ser a imagem de seu caráter.Cf. Möller, 2004, p. 143: "Nessa comparação, concede-se que o simular de qualidades necessárias é sempre possível. Fingere é, de fato (por vezes, em conexão com quasi ou videri), o leitmotiv de toda a passagem" [In diesem Vergleich wird konzediert, dass das Fingieren der erforderlichen Eigenschaften immerhin möglich ist. Überhaupt ist „fingere" (zumal in der Verbindung mit "quasi” oder "videri") geradezu letimotivischer Begriff dieser ganzen Passage.]. ${ }^{28}$ Cf. Fantham apud Leeman et alii, op. cit., p. 139. Cf. Wisse, op. cit., 1989, p. 230: “Exprimere denota a 'descrição' (não 'expressão')" [ "Exprimere” denotes the 'description' (not 'expression').]. 
Estamos próximos de uma distinção que se aproxima da categoria de persona poética, ${ }^{29}$ mas não se assume claramente a possibilidade de se construir um caráter fictício, "artificial", do orador no discurso, pois o ethos preexistente do uir bonus continua a desempenhar papel predominante. Assim, embora mais de uma vez se faça a associação entre oratória e poesia, não se tiram as conclusões que poderiam apoiar a ideia de que o autor empírico de uma composição literária pode se expressar em primeira pessoa assumindo um ethos que não é o seu, construindo no discurso mores diversos dos seus, segundo um certo decoro.

Em Quintiliano, ${ }^{30}$ na tradição catoniana do uir bonus peritus dicendi, ${ }^{31}$ o ethos revelará os mores preexistentes do orador (quo mores dicentis ex oratione perluceant et quodam modo agnoscantur ("para que o caráter de quem discursa, a partir do discurso, brilhe e de algum modo seja reconhecido" - VI, 2, 13).

Em certa passagem, Quintiliano - para quem não existe em latim uma tradução adequada do termo grego $-{ }^{32}$ diz que o orador deve apresentar o ethos de um homem de bem e afável: bonum et comem uirum (VI, 2, 18). O orador deve mostrar que tem tais qualidades ou fazer crer que as tem". ${ }^{33}$ Prevê-se, pois, a possibilidade de um ethos construído pelo orador sem vínculo com suas qualidades reais, preexistentes.

No De oratore, ao tratar do pathos, uma das três formas de "provas" na tradição aristotélica, Antônio defende que o orador deve de fato sentir os afetos que pretende provocar nos juízes:

\footnotetext{
${ }^{29} \mathrm{Um}$ poeta pode se expressar "através de um personagem", como Plauto, sub persona militis, no Truculento, 5 segundo Aulo Gélio (XIII, 23, 11), ou "em seu próprio nome", ex persona poetae (Veleio Patérculo, I, 3, 3, em referência a Homero), mas não se expressa, pelo que nos tem sido dado ver, nas letras latinas, a ideia de um poeta falando em primeira pessoa, ex persona, sem que essa persona corresponda ao autor empírico.

${ }^{30}$ Trechos desse autor serão citados a partir da edição de Winterbottom.

31 O dito catoniano, conservado por fontes várias, é assim reconstituído pela edição UTET: Orator est, Marce fili, uirbonus, dicendi peritus (Ad Marcum filium, fr. 18 - cf. Cugusi e Cugusi, 2001, p. 434). A posição catoniana tem embasamento em ideias estoicas (cf. Krostenko, 2001, p. 135). Cf. Quintiliano II, 15, 34, apoiando a definição de retórica como "ciência do falar bem" (bene dicendi scientiam): "Pois abrange todas as virtudes do discurso e, ao mesmo tempo, também os costumes do orador, uma vez que só pode discursar bem o homem bom" [Nam et orationis omnes uirtutes semel complectitur et protinus etiam mores oratoris, cum bene dicere non possit nisi bonus.].

${ }^{32}$ Cuius nomine, ut ego quidem sentio, caret sermo Romanus (VI, 2, 8).

${ }^{33}$ Quas virtutes... ipse aut habeat aut habere credatur (VI, 2, 18).
} 
II, 189. Neque fieri potest ut doleat is qui audit, ut oderit, ut inuideat, ut pertimescat aliquid, ut ad fletum misericordiamque deducatur, nisi omnes illi motus, quos orator adhibere uolet iudici, in ipso oratore impressi esse atque inusti uidebuntur.

Nem pode se dar que o ouvinte sofra, odeie, inveje, tema algo, seja levado ao pranto e à misericórdia, se todos esses afetos que o orador deseja provocar no juiz não parecerem estar gravados a ferro e fogo no próprio orador.

Se o orador, em seu discurso, não sente dor num momento de pathos, não só se perderá o efeito patético como se há o risco de provocar riso, em vez de lágrimas. ${ }^{34}$ Assim, é útil deixar-se tomar pelos afetos que se quer provocar, diz Antônio tratando de pathos ${ }^{35}$ mas ao tratar do ethos, não fica claro que o orador deva sempre possuir as qualidades que pretende lhe sejam reconhecidas através de seu discurso.

${ }^{34}$ Si dolor afuisset meus, non modo non miserabilis, sed etiam inridenda fuisset oratio mea (II, 196).

${ }^{35}$ O que não significa, propriamente, "sinceridade", segundo Wisse, 1989, p. 297: "Trata-se de uma demanda de efetividade, mas alguns tomam isso como se fosse de sinceridade. $O$ texto, se lido com algum cuidado, não encoraja essa confusão: não se afirma que o orador sentirá ele próprio as emoções se ele está convencido da retidão do caso que está defendendo, mas que é, além de necessário, também possível senti-las porque seu próprio discurso o arrebata e porque sua reputação está em jogo" [This is a demand for effectivity, but it is taken by some to be one for sincerity. The text, if read with some care, does not encourage this confusion: it is not claimed that the orator will feel the emotions himself if he is convinced of the justness of the case he is defending, but that it is, besides necessary, also possible to feel them because his own speech will carry him along and because his own reputation is at stake.]. De fato, não diríamos que um ator é "sincero" quando demonstra sentimentos ao recitar seu papel (cf. a imagem do ator recitando Pacúvio).

${ }^{36} \mathrm{O}$ relevo dado ao efeito psicagógico das paixões para a persuasão parece em contradição com a Retórica aristotélica, que critica os tratados predecessores por dar tanta importância a esse aspecto externo ao caso em si e nenhuma atenção aos entimemas. Não é conveniente "desviar" o juiz para a ira, o medo ou o ódio

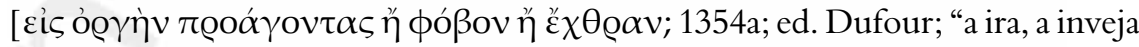
( $\phi \theta$ óvo) ou a piedade ( $\varepsilon \varepsilon \varepsilon \sigma v)$ ", ed. Ross]. Aristóteles, porém, não só reconhece o poder persuasivo das emoções na oratória como dedica seu segundo livro ao tema das paixões, o primeiro tratamento sistemático do assunto que nos legou a Antiguidade (cf. Kennedy, 1991, p. 122). 
Mas, como observa Wisse (1989, p. 262), o próprio Antônio também abre espaço para o "fingimento" do afeto em:

II, 189. Quod si fictus dolor suspiciendus esset et si in eius modi genere orationis nihil esset nisi falsum atque imitatione simulatum, maior ars aliqua forsitan esset requirenda.

E se se devesse assumir uma dor fingida e se num tal gênero de discurso não existisse nada que não fosse falso e simulado pela imitação, talvez fosse necessária uma arte maior.

Fictus dolor... como não lembrar da "dor fingida" do poema "Autopsicografia" de Pessoa?

O poeta é um fingidor.

Finge tão completamente

Que chega a fingir que é dor

A dor que deveras sente.

Mas, se na actio do orador a "dor fingida" é a que não tem raízes numa dor real, em Pessoa mesmo a dor real será, na obra poética, fingida.

Que o verbo fingere, na retórica, pode ser empregado para denotar algo que se inventou e não é, portanto, verdadeiro, mostram-no duas passagens que tratam da narratio. Nas palavras de um dos participantes do diálogo supostamente reproduzido no De oratore, II, o orador, no intuito de mover o riso, contará uma história espirituosa: pode ser falsa, ou, se verdadeira, entremeada de pequenas mentiras (siue habeas uere quod narrare possis, quod tamen est mendaci unculis aspergendum, siue fingas - 241). Note-se fingas. Admite-se que o orador minta (veja-se a oposição com uere) para provocar o riso...

Quintiliano, tratando da narratio, também admite a "falsidade" verossímil (quando bem-intencionada, destinada a salvar um inocente). Da longa passagem (IV, 2, 34-45), destacamos:

IV, 2, 34. Sunt enim plurima uera quidem, sed parum credibilia, sicut falsa quoque frequenter ueri similia. Quare non minus laborandum est ut iudex quae uere dicimus quam quae fingimus credat.

De fato, há muitíssimas coisas verdadeiras, mas pouco críveis, assim como também as falsas são frequentemente verossímeis. Por isso, é 
preciso se esforçar para que o juiz creia tanto no que dizemos com verdade quanto no que inventamos.

Contrasta-se, aqui, um uere dicere e um fingere que pode fazer o que é falso parecer verossímil. De fato, em XII, 1, 36 et seq., Quintiliano parece estar às voltas com um problema ético que o leva a justificar como pode um uir bonus dizer algo que não é verdadeiro:

Verum et illud, quod prima propositione durum uidetur, potest adferre ratio, ut uir bonus in defensione causar uelit auferre aliquando iudici ueritatem. Quod si quis a me proponi mirabitur (quamquam non est haec mea proprie sententia, sed eorum quos grauissimos sapientiae magistros aetas uetus credidit), etc.

Mas também isto, que, à primeira vista, parece duro, a razão pode recomendar: que o homem de bem, na defesa de uma causa, queira por vezes esconder do juiz a verdade. E se alguém se admirar pelo fato de eu o propor (embora esta não seja uma ideia propriamente minha, mas sim daqueles que as priscas eras acreditaram ser os mais respeitáveis mestres de sabedoria)", etc.

Em II, 17, 19, Quintiliano responde às críticas de que a retórica, assentando-se em "falsas opiniões", não pode ser uma "arte":

Ego rhetoricen nonnumquam dicere falsa pro ueris confitebor, sed non ideo in falsa quoque esse opinione concedam, quia longe diuersum, est ipsi quid uideri et ut alii uideatur efficere [... I Item orator, cum falso utitur pro uero, scit esse falsum eoque se pro uero uti: non ergo falsam habet ipse opinionem, sed fallit alium.

Quanto a mim, admitirei que por vezes a retórica diz o falso em vez do verdadeiro, mas não atribuirei isso a uma opinião falsa, pois que é coisa muito diversa algo parecer a alguém e fazer com que pareça a um outro [...]. Do mesmo modo, o orador, quando usa o falso em vez do verdadeiro, sabe ser falso e que dele usa em vez do verdadeiro. Assim, não tem ele próprio uma falsa opinião, mas engana um outro.

Também em II, 17, 26-27, Quintiliano lida com uma espécie de dilema ético:

Vti etiam uitiis rhetoricen, quod ars nulla faciat, criminantur, quia et falsum dicat et adfectus moueat. Quorum neutrum est turpe, cum ex bona ratione proficiscitur, ideoque nec uitum; nam et mendacium dicere etiam sapienti 
aliquando concessum est...

Acusam a retórica de se servir até mesmo de vícios, o que nenhuma arte faria, pois que diz o falso e move os afetos. Nenhuma dessas coisas é torpe, quando tem um bom motivo e, por isso, não é vício. Afinal, até ao sábio se tem concedido, de vez em quando, dizer uma mentira...

Por fim, uma espécie de conclusão em II, 17, 36:

Non semper autem ei, etiamsi frequentissime, tuenda ueritas erit, sed aliquando exigit communis utilitas ut etiam falsa defendat.

Porém, nem sempre ele deverá ter em vista a verdade, ainda que isso seja o mais frequente; mas, por vezes, a utilidade pública reclama que defenda também coisas falsas.

Em Cícero não se encontra expressão tão clara de que, por vezes, o orador faltará com a verdade (com as melhores intenções, na visão de Quintiliano...), mas, ao longo do De oratore, a nosso ver, duas concepções de ethos se confrontam: apesar do destaque dado às qualidades preexistentes de orador e réu, aqui e ali aflora a concepção de que esse ethos pode ser simplesmente uma construção do discurso, inventando-se qualidades, forjando-se um ethos que na verdade o orador ou o réu não têm, a fim de conquistar a benevolência do auditório. Mais importante, como prova "técnica", ainda que se trate de qualidades realmente existentes, elas têm de tomar forma no discurso, têm de ser construídas e compostas num todo que tenha eficácia persuasiva.

$\mathrm{Na}$ expressão dos afetos, a performance do orador faz toda diferença: ele tem de dar a impressão de estar sendo realmente tomado pelas emoções que quer demonstrar diante dos juízes. Mas Antônio contrapõe esse fingimento da dor à sua própria expressão do afeto em sua atuação como advogado, apresentada como um caso pessoal:

II, 189. Nunc ego quid tibi, Crasse, quid ceteris accidat nescio; de me autem causa nulla est cur apud homines prudentíssimos atque amicissimos mentiar: non mehercule umquam apud iudices aut dolorem aut misericordiam aut inuidiam aut odium dicendo excitare uolui, quin ipse in commouendis iudicibus his ipsis sensibus, sed quos illos ad ducere uellem, permouerer.

Agora, não sei o que se passa contigo, Crasso, ou com os outros; eu, porém, não tenho nenhum motivo para mentir, estando 
entre pessoas tão sensatas e amigas: por Hércules, nunca desejei provocar, discursando diante dos juízes, dor, ou misericórdia, ou hostilidade, ou ódio, sem que, na comoção dos juízes, eu mesmo não me comovesse com esses mesmos afetos os quais eu desejava levá-los a sentir.

Antônio dá a entender que com outros oradores pode-se passar de maneira diversa, ou seja, que eles finjam, não os sentindo realmente, os afetos que desejam provocar nos juízes. Para ele, porém, não há necessidade alguma de "simulação e falsidade" (simulatione et fallaciis, 191), já que o próprio discurso comove o orador até mais do que os ouvintes (ibidem). A força mesma de sentenças e lugares-comuns (uis... sententiarum atque eorum locorum, ibidem) faz com que aflore uma emoção real. Antônio, aqui, prevê o espanto de um interlocutor diante do fato de um mesmo homem tantas vezes enraivecer-se, sofrer, ser incitado por todo tipo de movimento da alma (hominem totiens irasci, totiens dolere, totiens omni motu animi concitari); mais à frente, veremos Quintiliano recomendar sua estratégia para que o orador possa manifestar essa diversidade de afetos.

Destaquemos como Cícero, em sua obra retórica da maturidade ${ }^{37}$ e, depois, Quintiliano parecem dar atenção especial ao afeto dolor $;^{38}$ curiosamente o mesmo que Fernando Pessoa destaca em sua "Autopsicografia". Poder-se-ia pensar que Cícero emprega dolor com o sentido geral de páthos (sentido 4 de dolor no OLD); entretanto, em certas passagens de sua obra retórica, vemos claramente que dolor ${ }^{39}$ é, mais precisamente, $u m$ dos afetos a serem movidos pelo orador; por exemplo:

\footnotetext{
${ }^{37}$ No juvenil De inuentione I, 106 et seq., ao tratar da conquestio, "discurso que procura suscitar a misericórdia dos ouvintes" (Conquestio est oratio auditorum misericordiam captans) e mencionar dezesseis tópicos que podem ser empregados para fazer com que o auditório se comova, não há menção do sentimento dolor; o afeto enfatizado é misericordia.

${ }^{38}$ Não encontramos nada de semelhante na Retórica, de Aristóteles, que dedica uma extensa passagem (II, 1-11, 1378a-1388b) às "paixões", mó $\theta \eta$, tratadas por pares contrastivos.

${ }^{39}$ Por outro lado, devemos ressaltar que as palavras dolor e "dor", como é natural, não recobrem exatamente o mesmo campo semântico; em latim, dolor, além do sentido da palavra portuguesa, pode significar ira e indignação (ver ThLL), sentimentos certamente importantes na actio do orador romano. A associação de dolor a miseratio em Cícero parece-nos, porém, provar que em suas obras retóricas o substantivo é empregado com sentido semelhante ao do português "dor".
} 
De oratore, II, 189. Neque fieri potest ut doleat is qui audit, ut oderit, ut inuideat, ut pertimescat aliquid, ut ad fletum misericordiamque deducatur... ${ }^{40}$

Sobre o efeito provocado pelo discurso no ouvinte, lemos em Brutus, 188:

Gaudet dolet, ridet plorat, fauet odit, comntemnit inuidet, ad misericordiam inducitur, ad pudendum, ad pigendum, irascitur mitigatur, sperat timet.

Alegra-se, sofre, ri, chora, tem simpatia, odeia, despreza, inveja, é levado à misericórdia, à vergonha, ao arrependimento, enraivece-se, abranda-se, tem esperança, teme...

Este exemplo é particularmente interessante: ao acoplar os afetos em um par gaudet/ dolet, como ridet/ plorat, Cícero mostra ter em vista o afeto que o português traduz por "dor", não o sentido mais geral de dolor como comoção da alma em geral.

Note-se a associação entre misericordia/ miseratio, dolor e lágrimas em:

De oratore II, 190. Neque ad misericordiam adducetur, nisi tu ei signa doloris tui uerbis, sententiis, uoce, uoltu, conlacrumatione denique ostenderis.

Nem será levado à misericórdia se tu próprio não mostrares sinais de tua dor nas palavras, pensamentos, voz, semblante, enfim, no pranto.

II, 196. Non fuit haec sine meis lacrumis, non sine dolore magno miseratio...

Este apelo à misericórdia não se deu sem minhas lágrimas, sem grande dor.

Nas palavras de Antônio, a actio deve ser "variada, veemente, cheia de ânimo, cheia de paixão, cheia de dor, cheia de verdade" (uaria, uehemens, plena spiritus, plena doloris, plena ueritatis - De oratore, II, 73); dos vários sentimentos que podem ser manifestados na actio, só se menciona dolor. O orador Galba se inflamava de "uma certa dor natural" (naturalis quidam dolor-Brutus, 93).

\footnotetext{
${ }^{40}$ Ver a tradução do trecho já oferecida mais acima. Cf. II, 191: "E para que não pareça, eventualmente, desmesurado e espantoso que um homem tantas vezes se enraiveça, sinta dor, tantas vezes se concite por toda espécie de movimento da alma" [Ac ne forte magnum ac mirabile esse uideatur, hominem totiens irasci, dolere, totiens omni motu animi concitari........ De novo, dolere é empregado como uma das emoções, dentre outras, manifestadas na actio do orador.
} 
No Bruto, Cícero menciona uma lembrança pessoal: a Calídio, que tinha mostrado uma actio nada vigorosa, ao acusar Quinto Gálio de tentar envenená-lo, o orador indagara, entre outras coisas: Vbi dolor? (Brutus, 278). O fato de Calídio não ter demonstrado nenhuma emoção em sua actio, ao defender sua própria causa, ao passo que costumava defender outros da maneira mais veemente, mostraria que, no caso presente, ele está simplesmente fingindo (como se se tratasse de um mau ator):

"Tu istuc, M. Calidi, nisi fingeres, sic ageres...?” (ibidem)

"Se não estivesses fingindo isso, discursarias dessa forma?"

Falando das miserationes, Cícero conta que, numa defesa compartilhada por um grupo de advogados, a peroratio era deixada para ele, por sua excelência na expressão de uma dor que parecia natural; note-se o destaque dado a dolor: In quo uiderer excellere non ingenio sed dolore assequebar (Orator, 130): "No que eu conseguia parecer me destacar não pelo engenho, mas pela dor". Parece-nos que Cícero aqui ressalta suas qualidades de ator: conseguia dar a impressão (uiderer) de ser tomado por uma dor não simulada por seu engenho, mas de fato sentida. Ao iniciar o tratamento do pathos no Orator, é manifesta à importância maior que assume a miseratio: todo o capítulo 130 e, além disso, na sequência (131), ao tratar de outros afetos, novamente a expressão patética da dor é salientada:

Nec uero miseratione solum mens iudicum permouenda est - qua nos ita dolenter uti solemus ut puerum infantem in manibus perorantes tenuerimus, ut alia in causa excitato reo nobili, sublato etiam filio paruo, plangore et lamentatione complerimus forum, - sed est faciendum etiam ut irascitur iudex mitigetur, inuideat faueat, contemnat admiretur, oderit diligat, cupiat taedeat, speret metuat, laetetur doleat...

Não se deve, porém, mover o espírito dos juízes somente na miseratio, de que costumamos lançar mão de forma tão patética (lit. 'dolorosa') que, perorando, chegamos ao ponto de segurar nas mãos uma criança pequena e, em outra causa, fazendo levantar um réu da nobreza e erguendo seu filho pequeno, enchemos o fórum de pranto e lamento - mas se deve fazer também com que o juiz se enraiveça, abrandese, tenha hostilidade, simpatia, despreze, admire, alegre-se, sofra...

Só ao efeito patético doloroso é concedida aqui a amplificação constituída pela evocação de uma lembrança pessoal. Vemos que Cícero dá notável destaque 
à miseratio e à expressão convincente de dolor por parte do orador. ${ }^{41}$

Se em certas passagens de Cícero, tomarmos dolor como pathos, expressando a comoção da alma em geral, ainda assim é significativo que se escolha uma palavra que, em outros contextos do próprio Cícero, designa um afeto específico, arrolado entre uma série de outros afetos que o orador deve mover. Por outro lado, nas Tusculanas III, 7, ao tratar da tradução mais adequada do termo pathos no plural, Cícero propõe como equivalente perturbationes [animi], não dolores (mais adiante, tratando de Quintiliano, veremos outras passagens em que o afeto em relevo é, novamente, dolor).

No De oratore, o "fingimento" da dor, porém, é contraposto ao caso pessoal de Antônio, que diz sempre se ter deixado tomar por emoções reais. Nesse sentido, é interessante ver como "dor" e "verdade" são enunciadas lado a lado nesta passagem que já citamos sobre a actio ideal:

II, 73. Accedat oportet actio uaria, uehemens, plena animi, plena spiritus, plena doloris, plena ueritatis.

Deve-se acrescentar uma actio variada, veemente, cheia de ânimo, cheia de entusiasmo, cheia de dor, cheia de verdade.

Crasso, em III, 214, afirma que "os oradores são atores da própria verdade" (oratores, qui sunt ueritatis ipsius actores), ao passo que os atores são "imitadores da verdade" (imitatores autem ueritatis histriones). ${ }^{42} \mathrm{Na}$ sequência, em clara resposta a Antônio, que enfatizava a necessidade de realmente sentir os afetos que se quer provocar nos ouvintes, Crasso ressalta o papel da arte na manifestação das emoções; há necessidade de arte também aqui:

II, 215. Acsine dubio in omni re uincit imitationem ueritas, sed ea si satis in

\footnotetext{
${ }^{41}$ Sabe-se que Cícero em geral atuou como defensor e só em poucos casos, como acusador. Daí a presença preponderante da miseratio em suas perorações. "Cognatos de 'miser' são especialmente frequentes. O réu é infeliz e, por isso, merece a piedade dos juízes" [Cognates of "miser" are especially prominent. The defendant is wretched, and therefore desserves the pity of the judges. ], observa Winterbottom, em sua análise das perorações dos discursos de Cícero (op. cit., p. 223). É notável, mesmo assim, o destaque dado por Cícero ao sentimento dolor e à miseratio em seus tratados de retórica.

${ }^{42}$ Cf. Quintiliano X, 2, 11: "Além disso, tudo que é semelhante a uma outra coisa é, necessariamente, inferior àquilo que imita, como a sombra, com relação ao corpo, o retrato, com relação ao rosto, e a atuação dos histriões com relação aos afetos verdadeiros" [Adde quod quidquid alteri simile est necesse est minus sit eo quod imitatur, ut umbra corpore et imago facie et actus histrio numueris adfectibus.].
} 
actione efficeret ipsa per sese, arte profecto non egeremus.

E, sem dúvida, em tudo a verdade supera a imitação; mas se ela fizesse o bastante por si própria na actio, não precisaríamos, certamente, de arte alguma.

A sequência da passagem é esclarecedora:

II, 215. Verum quia animi permotio, quae maxime aut declaranda aut imitanda est actione...

Mas, uma vez que a emoção da alma, que deve ser manifestada ou imitada, sobretudo, na actio...

Crasso acabara de dizer que os atores imitam a verdade; na passagem acima, a emoção deve ser expressa pelo orador ou... imitada, como se ele também tivesse, de vez em quando, de ser ator, quando a arte vem fazer o papel da natureza, fingindo o orador uma emoção que deveras não sente. Como resume Wisse (1989, p. 262):

Emoções não fingidas são melhores e mais efetivas que as fingidas, mas devemos (em parte) simulá-las, se necessário. ${ }^{43}$

Ao tratar da voz na pronuntiatio, Quintiliano distingue afetos reais de fingidos, deixando claro que os dois tipos comparecerão na actio do orador:

XI, 3, 61. Sed cum sint alii ueri adfectus, alii ficti et imitati...

Mas, sendo os afetos verdadeiros, uns, outros fingidos e imitados...

Os primeiros carecem de arte e precisam ser disciplinados metodicamente (61); os segundos carecem de força natural (carent natura, 62). Quintiliano recomenda:

62. Ideoque in iis primum est bene adfici et concipere imagines rerum et tamquam ueris moueri.

$43[\ldots]$ unpretended emotions are better and more effective than feigned ones, but one must (partly) simulate if necessary. 
E, por isso, no que diz respeito a esses [afetos fingidos], o principal é se deixar bem afetar e conceber imagens das coisas deixando-se comover por elas, como se fossem verdadeiras.

De acordo com os afetos que se quer manifestar na actio, o orador deverá controlar sua voz, seus gestos, seu rosto, sobretudo este último (72). Tratando da peroratio, Quintiliano defende que o orador deve sentir as emoções que deseja transmitir, se quiser comover: ${ }^{44}$

VI, 2, 26. Summa enim, quantum ego quidem sentio, circa mouendos adfectus in hoc posita est, ut moueamur ipsi.

O mais importante, ao menos no meu modo de pensar, acerca do mover os afetos se assenta nisto: que nós mesmos nos comovamos.

O orador deverá, em sua simulação dos afetos, parecer de fato experimentar uma emoção verdadeira:

VI, 2, 27. Quare, in iisquae esse ueri similia uolemus, simus ipsi símiles eorum qui uere patiuntur adfectibus, et a tali animo proficiscatur oratio qualem facere iudici uolet. An ille dolebit qui audiet me, qui in hoc dicam, non dolentem? Irascetur, si nihil ipse qui in iram concitat ei quod exigit simile patietur? Siccis agentis oculis lacrimas dabit? Fieri non potest...

Por isso, no que desejarmos que seja verossímil, sejamos nós mesmos semelhantes aos que de fato experimentam os afetos e que nosso discurso provenha de um ânimo tal qual o que desejamos provocar no juiz. Ou ele sentirá dor ao ouvir a mim, que me expresso sem sentir dor? Sentirá ira, se a pessoa mesma que incita à ira não experimenta nada de semelhante àquilo que pretende? Diante dos olhos secos do advogado, derramará lágrimas? Não é possível...

Notemos o contraponto da expressão da emoção do orador com a dos afetos verdadeiros (uere). Diante da dificuldade de mover afetos que não estão em nosso poder (29), Quintiliano propõe um método: evocar à mente "imagens de coisas ausentes" que provoquem a emoção (fantasi/ aj ou uisiones, como traduz Quintiliano, 29): Has quisquis bene ceperit is

\footnotetext{
${ }^{44}$ Quintiliano, como se sabe, traduz $\pi \alpha ́ \theta$ os por adfectus: VI, 2, 20. "Diverso disto é o que se chama $\pi \dot{\alpha} \theta o \varsigma$ e que nós denominamos, com propriedade, "afeto" [Diuersum est huic quod $\pi \alpha \dot{\theta} \theta$ o dicitur quodque nos adfectum proprie uocamus.].
} 
erit in adfectibus potentissimus ("Quem as elaborar de forma adequada terá grande poder sobre os afetos”, 30). Demonstrando o espírito prático de quem instrui didaticamente um futuro orador, Quintiliano sugere um método para que se possa, no momento adequado da actio, manifestar convincentemente, como um bom ator, os afetos que se deseja provocar no juiz.

Uma outra sugestão prática (note-se, novamente, o destaque dado a dolor):

VI, 2, 34. Vbi uero miseratione opus erit, nobis ea de quibus queremur accidisse credamus, atque id animo nostro persuademus. Nos illi simus quos grauia indigna tristia passos queremur, nec agamus rem quasi alienam, sed absumamos parum per illum dolorem: ita dicemus quae in nostro simili casu dicturi essemus.

Mas, quando for preciso 'comiseração', acreditemos que aconteceram a nós as coisas das quais nos queixamos e disso persuadamos nosso espírito. Tornemo-nos aqueles que nos queixamos de ter suportado coisas graves, imerecidas, tristes e não defendamos a causa como se nos fosse alheia, mas assumamos por pouco tempo aquela dor: assim diremos o que haveríamos de dizer em um caso semelhante que tivesse acontecido conosco.

Como em Cícero, ${ }^{45}$ Quintiliano cita em apoio de suas ideias uma anedota de cunho pessoal: ele teria visto atores que, deposta a máscara, choravam, ${ }^{46}$ um passo que claramente ecoa a anedota ciceroniana. ${ }^{47}$

Ao assumir a "máscara" do órfão, do náufrago ou de quem corre perigo, é preciso também "assumir os afetos" correspondentes (VI, 2, 36). Quintiliano dá seu testemunho pessoal: frequentemente se comoveu

\footnotetext{
${ }^{45}$ O texto do De oratore II, 193, algo corrompido, é assim reproduzido na série Les Belles Lettres: "Eu mesmo vi muitas vezes como pareciam arder através da máscara os olhos de um ator ao dizer estes versos famosos"... [Saepe ipse uidi, ut ex persona mihi ardere oculi homines histrionis uiderentur spondaulia illa dicentis...].

${ }^{46}$ Inst. Oratoria, VI, 2, 35: "Vi, pessoalmente, muitas vezes, atores, e até mesmo comediantes, depois de tirar a máscara após alguma ação de mais impacto, saírem de cena chorando" [Vidi ego saepe histriones atque comoedos, cum ex aliquo grauiore actu personam deposuissent, flentes adhuc egredi.].

${ }^{47}$ Notem-se as semelhanças: uidi ego saepe/ saepe ipse uidi. Como em Quintiliano, o Antônio de Cícero menciona um testemunho pessoal a respeito da emoção real sentida pelo ator ao representar uma cena.
} 
tanto que se viu afetado, de repente, não apenas por lágrimas, mas por uma palidez e uma dor semelhante à verdadeira (frequenter motus sum ut me non lacrimae solum deprenderent, sed pallor et uerisimilis dolor, ibidem). Uma dor não verdadeira, mas semelhante à verdadeira. Como amiúde, a comparação teatral: ${ }^{48}$ o orador sente em si os afetos como o ator que desempenha seu papel e sente as emoções como se se tratasse da vida real. Aqui, também, seria fácil transpor para o âmbito da persona poética a analogia, mas Quintiliano não o faz.

Para Sêneca, o orador expressa afetos que na verdade finge ter, como no caso da ira; não se tratará, pois, de "mover" a audiência por sentir na pele os afetos, mas por ser ator convincente (ressalte-se a comparação com o teatro que encontramos em Cícero e Quintiliano):

De ira, II, 17, 1. "Orator", inquit, "iratus aliquando melior est". Immo imitatus iratum; nam et histriones in pronuntiando non irati populum mouent, sed iratum bene agentes; et apud iudices itaque et in contione et ubicumque alieni animi ad nostrum arbitrium agendi sunt, modo iram, modo metum, modo misericordiam, ut aliis incutiamus, ipsi simulabimus, et saepe $i d$, quod ueri adfectus non effecissent, effecit imitatio adfectuum.

"O orador", diz-se, "por vezes é melhor quando está irado". Precisemos: quando imita um irado; de fato, também os atores, ao representar, não comovem o público por estarem irados, mas porque representam bem o papel de irado; tanto diante do juiz, quanto numa assembleia e onde quer que se deva mover os ânimos alheiros ao nosso arbítrio, nós mesmos simularemos ora a ira, ora o medo, ora a misericórdia, para os incutirmos nos outros, e muitas vezes o que afetos verdadeiros não teriam produzido, a imitação dos afetos produziu. ${ }^{49}$

Cícero, nas Tusculanas, também não recomenda que o orador sinta ira, mas apenas que a imite:

Tusculanae, IV, 55. Oratorem uero irasci minime decet, simulare non dedecet.

\footnotetext{
${ }^{48}$ Cf., em De oratore I, 128, as qualidades requeridas na actio: "Requer-se voz de atores trágicos, gestos quase iguais aos dos maiores atores" [Vox tragoediorum, gestus paene summorum actorum est requirendus.].

${ }^{49}$ Não se expressa aqui uma rejeição do fingimento da cólera nos tribunais; ao que parece, não se conhece a posição dos estoicos a esse respeito (cf. Wisse, 1989, p. 267).
} 
An tibi irasci tum uidemur, cum quid in causis acrius et uehementius dicimus?

Ao orador, de fato, não convém minimamente sentir ira, simulá-la não desconvém. Ou te parecemos sentir ira quando, nas causas, dizemos algo de forma mais áspera e veemente?

Assumindo a persona do preceptor de filosofia e combatendo as "perturbações da alma", Cícero adota nessa passagem posição contrária à defendida por Antônio no De oratore. Nesse diálogo, não se trata apenas de fingir um afeto, mas, de fato, senti-lo: Antônio pergunta como não seria tomado de grande dor ao perorar num processo em que se tratava da perda de direitos políticos de Mânio Aquílio, em que não era o "ator" de um personagem diferente, mas o "autor" de sua própria persona:

II. 194. Quare nolite existimare me ipsum, qui non heroum ueteres casus fictosque luctus uelim imitari atque adumbrare dicendo - neque actor sum alienae personae, sed auctor meae -, cum mihil $M^{\prime}$ Aquilius in ciuitate retinendus esset, quae in illa causa peroranda fecerim sine magno dolore fecisse.

Por isso, não penseis que eu, que não quero imitar e copiar, discursando, os antigos infortúnios dos heróis e lutos fingidos - nem sou ator de um personagem alheio, mas autor do meu próprio quando se tratava de reter na cidade a Mânio Aquílio, o que fiz ao perorar naquela causa o fiz sem grande dor.

Detenhamo-nos um pouco nessa última passagem. Podemos interpretar assim as palavras de Antônio: naquele processo, eu não representava um personagem (com sentimentos alheios a mim), mas criava (auctor) uma persona, um papel para representar a mim mesmo (o tradutor da Belles Lettres traz devant les juges je ne recours pas à un masque d'emprunt: le rôle que je remplis est le mien).${ }^{50} \mathrm{O}$ tradutor da Loeb não nos parece feliz ao dizer presenting my own personality and not representing another's: ${ }^{51}$ ao igualar persona a personalidade, deixa-se de lado a ideia de uma construção retórica de certo ethos. Necessário observar, porém, que o sentido a dar a auctor nesta passagem não é óbvio. Se se deve interpretar como em certa tradução para o inglês, que julgamos plausível: I am not an actor of another's character, but the author of my own, como lemos numa tradução recente, ${ }^{52}$ fica

\footnotetext{
${ }^{50}$ Cícero, 1966, p. 95.

${ }^{51}$ Cícero, 1967, p. 339.

${ }^{52}$ Cícero, 2001, p. 174.
} 
clara a ideia de uma construção da própria persona pelo orador. Na causa evocada por Antônio, a comoção expressa era, de fato, sentida pelo orador (misericordia sum ipse captus, 194), não havendo, pois, necessidade de fingir a dor. Mas, ao expressar afetos que de fato sente, Antônio ainda assim está representando um papel, o dele próprio; as fronteiras entre ficção e realidade se confundem: Antônio "representa" uma dor que deveras sente. A performance do orador é um palco; sua atuação, uma actio parecida com a teatral; sentimentos reais submetem-se ao jogo da enunciação discursiva: são encenados, por mais reais que sejam; necessitam de um autor para elaborar uma persona específica, com palavras, sentimentos e atos a ela adequados.

Em De oratore II, 102, Antônio conta como se prepara para um processo judicial: sem presença de terceiros, o réu é incitado por ele a informá-lo sobre sua causa; Antônio defende a causa do adversário para obrigar o réu a defender a sua e expressar tudo o que pensa sobre ela. Quando o réu parte, Antônio desempenha três papéis, o dele próprio, o do adversário e o do juiz, com a mesma imparcialidade:

Itaque quom ille discessit, tris personas unus sustineo summa animi aequitate: meam, aduersari, iudicis. ${ }^{53}$

E assim, quando ele parte, eu, sozinho, assumo três papéis com a maior imparcialidade possível: o meu, o do adversário e o do juiz.

De novo, a performance do orador é retratada como uma performance teatral, um papel que se desempenha; ser ego é desempenhar o papel de ego. Esse papel precisa ser cuidadosamente estudado e ensaiado, à semelhança do ensaio de um ator antes do espetáculo.

A retórica não perde de vista o efeito sobre o destinatário; nesse modelo de comunicação, ego é pensado do ponto de vista de sua avaliação pelo outro; não é uma questão de autenticidade ou sinceridade, mas de conseguir eficácia persuasiva construindo para o outro uma imagem de si que corresponda ao efeito que se quer nele provocar, os afetos que se

\footnotetext{
${ }^{53}$ Uma tradução como a da Les Belles Lettres: “Après qu'il m'a quitté, je remplis à moi seul trois rôles différents et, avec la plus complète impartialité, je prends successivement la place du défenseur, de l'adversaire et du juge”, perde a ideia mais surpreendente do original: a de que se desempenha também o próprio papel: meam (personam sustineo).
} 
deseja nele mover. O orador é um "fingidor" de si mesmo, porque tem de construir a imagem mais persuasiva de si próprio, não, simplesmente, apresentar-se tal como supostamente, naturalmente, é. Nesse sentido, parece-nos, a concepção de persona do orador está próxima da noção de eu poético que vemos no poema de Pessoa e da ideia comum de que, mesmo quando expressa sentimentos próprios, "Je est un autre", embora não encontremos, explicitamente, na teoria dos antigos romanos, a categoria da "persona poética" ou algo que lhe equivalha.

\section{Referências}

ARISTOTE. Rhétorique. Texte établi et traduit par M. Dufour. Paris: Les Belles Lettres, 1967. CICÉRON. De l'orateur: livre deuxième. Texte établi et traduit par Edmond Courbaud. Paris: Les Belles Lettres, 1966.

CICERO. De oratore. With an English translation by E, W. Sutton. London/ Cambridge, Mass.: William Heinemann/Harvard University Press, 1967.

CICERO. On the ideal orator ("De Oratore"). Translated, with introduction, notes, appendixes, glossary and indexes by James M. May and Jakob Wisse. New York/ Oxford: Oxford University Press, 2001.

CICERONE. Dell'oratore. Con un saggio introduttivo di Emanuele Narducci. $4^{\mathrm{a}}$. ed. Milano: Rizzoli, 1997.

CLAY, D. The theory of literary persona in Antiquity. Materiali e discussioni per l'analisi dei testi classici, Pisa, vol. 40, 1998, p. 9-40.

CUGUSI, P.; CUGUSI, M. T. S. Opere di Marco Porcio Catone Censore. Torino: Unione Tipografico Editrice Torinese, 2001.

FORTENBAUGH, W. W.; MIRHADY, D. C. (org.). Peripatetic rhetoric after Aristotle. New Brunswick/London: Transaction Publishers, 1994.

GUÉRIN, C. Persona, Lélaboration d'une notion rhétorique au Ier siècle AV.J.-C.Volume II. Paris: Librairie Philosophique J. Vrin, 2011.

HINDS, S. Allusion and intertext: dynamics of appropriation in Roman poetry. Cambridge: University Press, 1998.

KENNEDY, G. A. Aristotle, On rhetoric, a theory of civic discourse. New York/Oxford: Oxford University Press, 1991.

KROSTENKO, B. A. Cicero, Catullus and the language of social performance. Chicago/ London: University of Chicago Press, 2001.

LEEMAN, A. D.; PINSKTER, H.; RABBIE, E. M. Tullius Cicero De oratore libri III. 3. Band: Buch II, 99-290. Heidelberg: Carl Winter Universität Verlag, 1989.

$\overline{{ }^{54} \text { Cf. Clay, 1998, p. } 9}-40$ e Mayer, 2003, p. 55-80. 
MAY, J. M. Brill's companion to Cicero oratory and rhetoric. Leiden/Boston/Köln: Brill, 2002.

MAY, J. M. Trials of character: the eloquence of Ciceronian ethos. Chapell Hill/London: North Carolina Press, 1988.

MAYER, R. Persona < $>$ Problems: the literary person in Antiquity revisited. Materiali e discussioni per l'analisi dei testi classici, Pisa/ Roma,vol. 50, 2003, p. 55-80. M. FABI QVINTILIANI Institutionis oratoriae libri duodecim. Recognovit brevique adnotatione critica instruxit M. Winterbottom. Oxonii: E. Typographeo Clarendoniano, 1970.

MÖLLER, M. Talis oratio - qualis vita: zu Theorie und Praxis mimestischer Verfahren in der griechisch-römischen Literaturkritik. Heidelberg: Winter, 2004.

MONTEFUSCO, L. Cicerone, De oratore: la doppia funzione dell'ethos dell'oratore. Rhetorica: a journal of the history of rhetoric, vol. 10, n. 3, p. 245-257, 1992. POWELL, J.; PATERSON, J. (org.). Cicero the advocate. Oxford: University Press, 2006. PESSOA, F. Cancioneiro. Rio de Janeiro: Aguilar, 1976.

SCATOLIN, A. A invenção no "Do orador" de Cícero: um estudo à luz de "Ad Familiares"I, 9, 23. Tese de doutorado inédita. São Paulo: FFLCH-USP, 2009.

SENECA. Moral essays. With an English translation by John W. Basore. London/ Cambridge, Massachusetts: William Heinemann/Harvard University Press, 1963. WINTERBOTTOM, M. Peroration. In: POWELL, J.; PATERSON, J. (org.). Cicero the advocate. Oxford: University Press, 2006, p. 215-230.

WISSE, J. "De oratore": the orator, rhetoric and philosophy. In: MAY, J. M. (org.). Brill's companion to Cicero oratory and rhetoric. Leiden/Boston/Köln: Brill, 2002, p. 375-400.

WISSE, J. Ethos and pathos from Aristotle to Cicero. Amsterdam: Adolf M. Hakkert, 1989.

UELDING, G. (org.). Historisches Wörterbuch der Rhetorik. Band 2. Darmstadt: Wissenschaftliche Buchgesellschaft, 1994. 
